\title{
Thiophene-bithiazole based metal-free dye as DSSC sensitizer: Effect of co-adsorbents on photovoltaic efficiency
}

\author{
JAYANTHY S PANICKER ${ }^{\mathrm{a}, \mathrm{b}}$, BIJITHA BALAN ${ }^{\mathrm{a}, *}$, SURAJ SOMAN ${ }^{\mathrm{a}, *}$, \\ TANWISTHA GHOSH ${ }^{\mathrm{a}, \mathrm{b}}$ and VIJAYAKUMAR C NAIR ${ }^{\mathrm{a}, \mathrm{b}}$

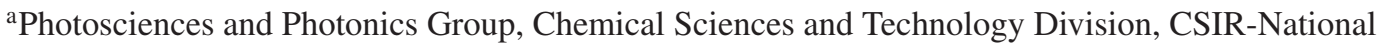 \\ Institute for Interdisciplinary Science and Technology (CSIR-NIIST), Trivandrum 695 019, India \\ ${ }^{b}$ Academy of Scientific and Innovative Research (AcSIR), Trivandrum 695 019, India \\ e-mail: bijithab1@gmail.com; suraj@ niist.res.in
}

MS received 24 August 2015; revised 7 October 2015; accepted 23 October 2015

\begin{abstract}
A new molecule consisting of a bithiazole chromophore sandwiched between two thiophenes, functionalized with benzothiophene unit at one end and cyanoacrylic acid at the other end (BT1) was synthesized, photophysical properties were studied and employed as a photosensitizer in dye-sensitized solar cells (DSSCs). The molecule exhibited an intense absorption in the UV-visible region with absorption extending up to $500 \mathrm{~nm}$. The ground and excited state potentials of BT1 were calculated to be 1.29 and $-0.65 \mathrm{~V}$, respectively $v s$. NHE using cyclic voltammetry. The ground state energy level is more positive than the triiodide electrolyte and excited state energy level is considerably more negative than the $\mathrm{TiO}_{2}$ satisfying the energetic requirements for a photosensitizer in DSSC. The solar cells fabricated from BT1 exhibited an efficiency of $1.13 \%$. The effect of various co-adsorbents (CDCA,TP1 andTP2) on the DSSC performance was investigated in detail. In the presence of CDCA, the photovoltaic efficiency was enhanced to $1.25 \%$, whereas, in the presence of TP1 and TP2, the efficiency lowered to $0.20 \%$ and $0.59 \%$, respectively. The increased efficiency in the presence of CDCA could be attributed to the prevention of the aggregation of dye molecules induced by CDCA. On the other hand, TP1 and TP2 were found to be not as effective as CDCA to prevent aggregation leading to the lowering of photoconversion efficiency.
\end{abstract}

Keywords. Dye sensitized solar cell; Thiophenes; Bithiazoles, co-adsorbents; photoconversion efficiency.

\section{Introduction}

Considering the adverse impact of the depletion of fossil fuels on the mankind, the need to find clean and abundant alternative energy resources is of paramount importance. Harvesting solar energy and converting it into electricity using photovoltaic technology is one of the most promising ways of addressing this issue. Among the various photovoltaic technologies, dye sensitized solar cells (DSSCs) have the potential to become a commercial success because of their low fabrication cost and respectable efficiency. ${ }^{1-6}$ Ruthenium dyes are the most commonly used sensitizers in DSSCs with the power conversion efficiency reaching up to $11.5 \% .^{7-10}$ A number of Zn-porphyrin dyes were also reported with efficiency reaching $13 \%$ in certain cases. ${ }^{11,12}$ In recent years, there is a widespread interest for the development of metal-free dyes for DSSC applications. ${ }^{13-19}$ Although the efficiency is less compared to the metal based dyes, the metal-free organic dyes have attracted considerable attention due to their lower cost, easy

\footnotetext{
*For correspondence
}

purification, tailor made design properties, etc. Triphenylamine derivatives are the most commonly used donors in organic based metal-free dyes. Interestingly, thiophene based conjugated systems are less explored in DSSCs, although many reports of molecules consisting of thiophene attached to triphenylamines are there. ${ }^{20-28}$

In the present work, we have designed and synthesized a thiophene based donor-acceptor system, BT1, which consists of benzothiophene unit at one end, a bithiazole unit sandwiched between two thiophene units as the linker and cyanoacrylic acid acting both as the acceptor and anchoring group to $\mathrm{TiO}_{2} .{ }^{29}$ Bithiazoles are relatively weak acceptors and widely used as a constituent in oligomers and polymers for organic bulk heterojunction solar cell devices. ${ }^{30,31}$ However, only a few number of bithiazole based systems are designed for DSSC application. ${ }^{32-36}$ BT1 is incorporated with four $n$-hexyl chains in order to get sufficient solubility for solution processing. It is known that improvement of open circuit voltage $\left(V_{\mathrm{OC}}\right)$ and short circuit current $\left(J_{\mathrm{SC}}\right)$ could be achieved by preventing $\pi-\pi$ stacking of organic dye molecules. ${ }^{33}$ Co-adsorbents are commonly used for this purpose. To study the effect of 


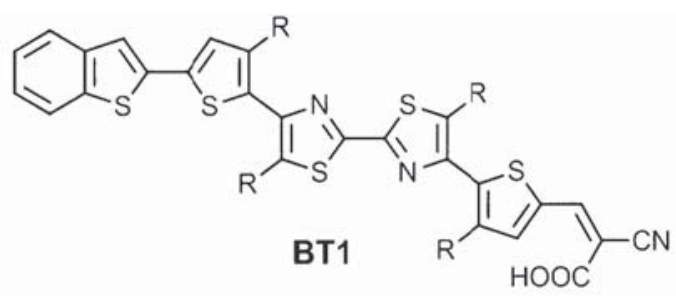

Co-adsorbents
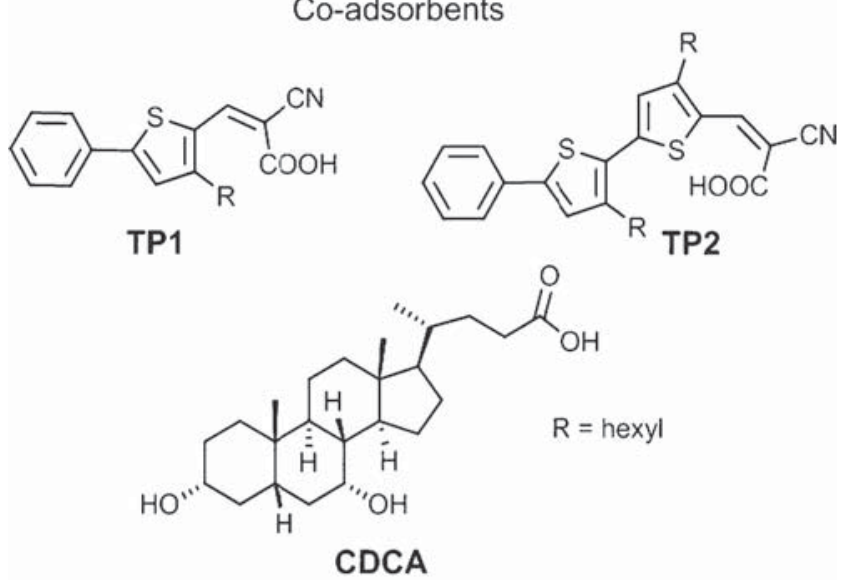

Chart 1. Structure of the molecules used in the study.

co-adsorbents on the performance of BT1, we have selected a commercially available molecule, chenodeoxycholic acid (CDCA). In addition to that, two new co-adsorbents having similar thiophene-cyanoacrylic acid anchoring group as that of BT1 (TP1 and TP2) were synthesized. Chemical structure of the sensitizer and co-adsorbents are depicted in Chart 1 . In the present work, our aim is to use TP1 and TP2 as co-adsorbents for reducing recombination rate by preventing $\pi-\pi$ stacking interactions of BT1. The effect of different co-adsorbents on the photovoltaic performance of BT1 was analyzed using incident photon-to-current conversion efficiency (IPCE) measurement, photocurrentvoltage $(J-V)$ curves, electron lifetime analysis, and electrochemical impedance spectroscopy.

\section{Experimental}

\subsection{Materials and characterization techniques}

The reagents and materials for synthesis were purchased from Sigma-Aldrich, Merck, TCI and Spectrochem chemical suppliers, and used as received. Air and water sensitive synthetic steps were performed in an argon atmosphere using standard Schlenk techniques. ${ }^{1} \mathrm{H}$ and ${ }^{13} \mathrm{C}$-NMR spectra were recorded using Bruker-500 MHz spectrometer. Absorption spectra were recorded using Shimadzu UV-Visible-2401PC spectrophotometer. Steady-state fluorescence experiments were performed using a SPEX Fluorolog F112X spectrofluorimeter. CV experiments were performed using a BAS 50W voltammetric analyser. Density functional theory (DFT) calculations were performed at the B3LYP/6-31G* level using Gaussian 09 program.

\subsection{Synthesis}

BT1 was synthesized as shown in scheme 1. Compounds 1-4 were already reported in literature.$^{37} \mathrm{Com}$ pound 4 was formylated using Vilsmeier reaction to give 5, which was then brominated using NBS to give 6. Stille coupling of $\mathbf{6}$ with benzo[b]thiophen-2yl tributylstannane gives $\mathbf{7}$, which was then reacted with cyanoacetic acid to give BT1. The molecule was characterized using ${ }^{1} \mathrm{H}$ NMR, ${ }^{13} \mathrm{C}$ NMR and $\mathrm{CHN}$.

2.2a Synthesis of 5: A Vilsmeier reagent was prepared in cold condition using $\mathrm{POCl}_{3}(0.33 \mathrm{~mL}, 3.5 \mathrm{mmol})$ and DMF (1.2 mL, $16.1 \mathrm{mmol})$ in a RB flask under Nitrogen atmosphere. Then it was transferred to compound 4 ( $1.2 \mathrm{~g}, 1.7 \mathrm{mmol})$ in anhydrous dichloroethane $(12 \mathrm{~mL}) \mathrm{kept}$ at $0^{\circ} \mathrm{C}$ under Nitrogen atmosphere. After being stirred for $2 \mathrm{~h}$ at $0^{\circ} \mathrm{C}$, it was refluxed at $60^{\circ} \mathrm{C}$ for $12 \mathrm{~h}$. The reaction mixture was poured into ice cold water $(200 \mathrm{~mL})$, neutralized with $\mathrm{Na}_{2} \mathrm{CO}_{3}$, and extracted with chloroform. The combined organic layer was washed with water and dried over magnesium sulphate. After removal of solvent, it was purified by column chromatography (silica gel, $50 \% \mathrm{CH}_{2} \mathrm{Cl}_{2}$-hexane) to afford a greenish yellow viscous liquid (Yield: 63\%). ${ }^{1} \mathrm{H} \mathrm{NMR}\left(500 \mathrm{MHz}, \mathrm{CDCl}_{3}\right) \delta 9.89(\mathrm{~s}, 1 \mathrm{H}), 7.67(\mathrm{~s}, 1 \mathrm{H})$, $7.37(\mathrm{~d}, 1 \mathrm{H}), 7.00(\mathrm{~d}, 1 \mathrm{H}), 2.67-2.72(\mathrm{~m}, 4 \mathrm{H})$, $2.59\left(\mathrm{t}, 2 \mathrm{H}, \mathrm{J}_{1}=8 \mathrm{~Hz}, \mathrm{~J}_{2}=7.5 \mathrm{~Hz}\right), 2.54(\mathrm{t}, 2 \mathrm{H}$, $\left.\mathrm{J}_{1}=7.5 \mathrm{~Hz}, \mathrm{~J}_{2}=8 \mathrm{~Hz}\right), 1.66-1.72(\mathrm{~m}, 4 \mathrm{H}), 1.22-$ $1.30(\mathrm{~m}, 28 \mathrm{H}), 0.85(\mathrm{~m}, 12 \mathrm{H}) .{ }^{13} \mathrm{C}$ NMR $(125 \mathrm{MHz}$, $\left.\mathrm{CDCl}_{3}\right) \delta 180.99,159.54,157.82,156.30,155.81$, $142.83,141.77,141.40,135.69,134.40,127.15$, $124.58,124.21,123.26,121.68,29.83,29.79,29.77$, $28.80,28.58,28.14,27.91,27.88,27.79,27.30,27.24$, $27.18,20.77,20.74,12.33,12.26,12.23$. HRMS: $\mathrm{m} / \mathrm{z}=$ $697.33\left(\mathrm{M}^{+}+\mathrm{H}\right)$.

2.2b Synthesis of 6: Compound 5 (240 mg, 0.344 $\mathrm{mmol}$ ) was dissolved in a mixture of chloroform $(14 \mathrm{~mL})$ and glacial acetic acid $(3.84 \mathrm{~mL}) . \quad N$ Bromosuccinimide (122.54 mg, $0.688 \mathrm{mmol}$ ) was added in small portions, and the reaction mixture was stirred in the dark for $4 \mathrm{~h}$ at room temperature. The reaction mixture was then added to water and extracted with chloroform. The crude product was purified by column chromatography (silica gel, $50 \% \mathrm{CH}_{2} \mathrm{Cl}_{2}$-hexane) to 

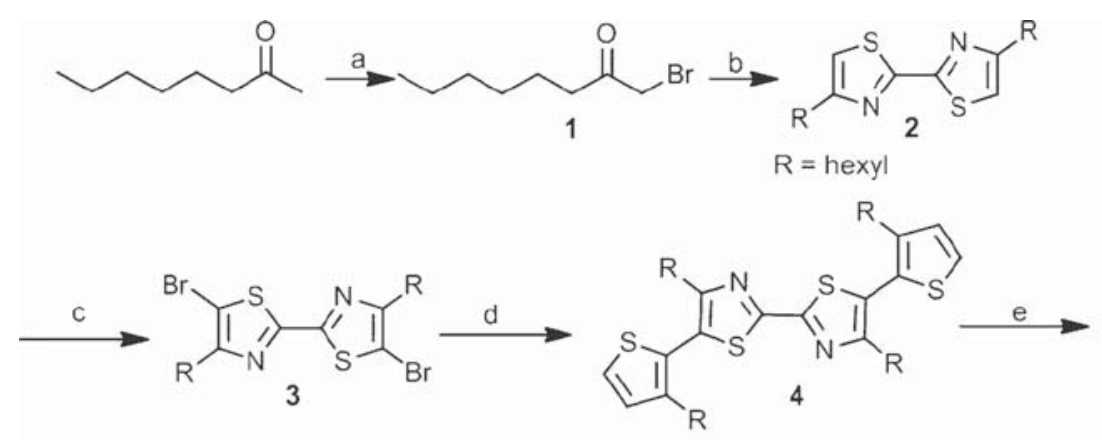<smiles>[R]c1cc(C=O)sc1-c1sc(-c2nc([R])c(-c3sc(-c4nc([R])c(-c5sc(C=O)cc5[R])s4)nc3[R])s2)nc1[R]</smiles><smiles>[R]c1cc(C=O)sc1-c1sc(-c2nc([R])c(-c3sc(-c4cc5ccccc5s4)cc3[R])s2)nc1[R]</smiles><smiles>[R]c1cc(-c2cc3ccccc3s2)sc1-c1sc(-c2nc(Br)c(-c3sc(/C=C(/C)C(=O)O)cc3[R])s2)nc1[R]</smiles>

Scheme 1. Synthetic route for the preparation of BT1. Reagents and conditions: (a) Bromine, Urea, Glacial acetic acid, 12 h; (b) Dithiooxamide, absolute ethanol, reflux, 4 h; (c) NBS, Glacial acetic acid, 3 h; (d) 3-Hexylthiophene-2boronic acid pinacol ester, $\mathrm{Pd}\left(\mathrm{PPh}_{3}\right)_{4}, \mathrm{~K}_{2} \mathrm{CO}_{3}$, Toluene, reflux, $24 \mathrm{~h}$; (e) $\mathrm{POCl}_{3}$, DMF, Dichloroethane, $0-60^{\circ} \mathrm{C}, 12 \mathrm{~h}$; (f) $\mathrm{NBS}, \mathrm{CHCl}_{3}$, Glacial acetic acid, 4 $\mathrm{h}$; (g) benzo[b]thiophen-2-yltributylstannane, $\mathrm{Pd}\left(\mathrm{PPh}_{3}\right)_{4}$, Toluene, $16 \mathrm{~h}$, reflux; (h) Cyanoacetic acid, Piperidine, $\mathrm{CHCl}_{3}$, reflux, $30 \mathrm{~h}$.

afford the product $\mathbf{6}$ as a yellow solid which was recrystallized from hot methanol. (Yield: 82\%). ${ }^{1} \mathrm{H}$ NMR (500 $\left.\mathrm{MHz}, \mathrm{CDCl}_{3}\right) \delta 9.89(\mathrm{~s}, 1 \mathrm{H}), 7.67(\mathrm{~s}, 1 \mathrm{H}), 6.96(\mathrm{~s}, 1 \mathrm{H})$, 2.66-2.72(m, 4H), $2.59\left(\mathrm{t}, 2 \mathrm{H}, \mathrm{J}_{1}=7.5 \mathrm{~Hz}, \mathrm{~J}_{2}=\right.$ $8 \mathrm{~Hz}), 2.48\left(\mathrm{t}, 2 \mathrm{H}, \mathrm{J}_{1}=7.5 \mathrm{~Hz}, \mathrm{~J}_{2}=8 \mathrm{~Hz}\right), 1.22-$ $1.72(\mathrm{~m}, 32 \mathrm{H}), 0.84-0.87(\mathrm{~m}, 12 \mathrm{H}) .{ }^{13} \mathrm{C}$ NMR $(125$ $\left.\mathrm{MHz}, \mathrm{CDCl}_{3}\right) \delta 182.78,161.06,160.08,158.16,158.10$, $144.65,144.38,143.23,137.48,136.03,131.73$, $126.50,124.49,123.73,113.10,31.58,31.55,31.53$, $30.42,30.36,29.91,29.71,29.57,29.02,28.99,28.96$, 28.91, 22.56, 22.55, 22.53, 14.06, 14.03, 14.02. HRMS: $m / z=777.24\left(\mathrm{M}^{+}+\mathrm{H}\right)$.

2.2c Synthesis of 7: Compound 6 (220 mg, $0.28 \mathrm{mmol})$ and benzo[b]thiophen-2-yltributylstannane $(120.1 \mathrm{mg}$, $0.28 \mathrm{mmol}$ ) were weighed into a two-necked RB flask and dissolved in dry toluene $(6 \mathrm{~mL})$. Air was removed from the flask and filled with nitrogen by applying freeze-pump-thaw method for three times. $\mathrm{Pd}\left(\mathrm{PPh}_{3}\right)_{4}$ (38 mg, $0.02 \mathrm{mmol}$ ) was added under $\mathrm{N}_{2}$ counter flow and the reaction mixture was refluxed at $110^{\circ} \mathrm{C}$ for 16 $\mathrm{h}$. The reaction mixture was then poured into water and extracted with chloroform. The combined organic fraction was dried over $\mathrm{Na}_{2} \mathrm{SO}_{4}$ and evaporated to dryness under reduced pressure. The resulting crude product was purified by column chromatography (silica gel, $50 \% \mathrm{CH}_{2} \mathrm{Cl}_{2}$-hexane) to afford product as a yellow oil. (Yield: $84 \%)$. ${ }^{1} \mathrm{H}$ NMR $\left(500 \mathrm{MHz}, \mathrm{CDCl}_{3}\right) \delta 9.89$ (s, 1H), $7.79(\mathrm{~d}, 1 \mathrm{H}), 7.74(\mathrm{~d}, 1 \mathrm{H}), 7.67(\mathrm{~s}, 1 \mathrm{H}), 7.30-7.36$ (m, 2H), 7.18 (s, 1H), 2.70-2.77 (m, 4H), 2.54-2.61 (m, 4H), 1.20-1.80 (m, 32H), $0.86(\mathrm{t}, 12 \mathrm{H}) .{ }^{13} \mathrm{C}$ NMR $\left(125 \mathrm{MHz}, \mathrm{CDCl}_{3}\right) \delta 181.79,160.14,158.82,157.13$, 156.81, 143.62, 143.49, 142.17, 139.27, 138.11, 136.89, 135.66, 135.08, 125.73, 124.31, 124.09, 123.76, 123.66, 
$122.62,122.51,121.15,118.96,30.58,30.52,30.41$, $29.49,29.35,29.15,28.91,28.82,28.58,28.09,28.01$, 27.95, 27.90, 21.56, 21.52, 13.06, 13.04, 13.01. HRMS: $m / z=829.33 .33\left(\mathbf{M}^{+}\right)$.

2.2d Synthesis of BT1: Compound 7 (40 mg, 0.048 $\mathrm{mmol})$ and 2-cyanoacetic acid (27.6 $\mathrm{mg}, 0.32 \mathrm{mmol})$ in chloroform $(3 \mathrm{~mL})$ were heated at $60^{\circ} \mathrm{C}$ for $30 \mathrm{~h}$. After cooling to room temperature, the mixture was added to water. The precipitate was isolated by filtration and washed with water. The residue was then purified by column chromatography (silica gel $80 \%$ $\left.\mathrm{CH}_{2} \mathrm{Cl}_{2}-\mathrm{EtOH}\right)$ to give a blackish red solid. It was again purified by precipitating from cold methanol. (Yield: 88\%). ${ }^{1} \mathrm{H}$ NMR $\left(500 \mathrm{MHz}, \mathrm{CDCl}_{3}\right) \delta 8.29$ (s, 1H), $7.79(\mathrm{~d}, 1 \mathrm{H}), 7.73(\mathrm{~s}, 2 \mathrm{H}), 7.41(\mathrm{~s}, 1 \mathrm{H})$, 7.31-7.35 (m, 2H), $7.18(\mathrm{~s}, 1 \mathrm{H}), 2.54-2.76(\mathrm{~m}, 8 \mathrm{H})$, 1.20-1.80 (m, 32H), $0.86(\mathrm{t}, 12 \mathrm{H}) \cdot{ }^{13} \mathrm{C}$ NMR $(125$ $\left.\mathrm{MHz}, \mathrm{CDCl}_{3}\right)$ 161.36, 159.71, 158.43, 157.87, 145.18, $144.59,140.30,139.29,139.17,138.01,137.55$, $136.67,135.66,126.77,125.61,125.01,124.79$, $124.71,123.55,123.30,122.18,120.03,31.62,31.61$, $31.56,31.53,30.53,30.38,30.06,29.82,29.64,29.62$, 29.14, 29.12, 29.07, 29.00, 28.80, 22.59, 22.55, 14.08, 14.04. Anal. Calcd. for $\mathrm{C}_{50} \mathrm{H}_{61} \mathrm{~N}_{3} \mathrm{O}_{2} \mathrm{~S}_{5}$ : C, 67.00; $\mathrm{H}$, 6.86; N, 4.69; S, 17.89\%. Found: C, 66.34; H, 6.901; N, 4.65; S, $16.97 \%$.

\subsection{Fabrication and Characterization of DSSC}

The FTO plates used for $\mathrm{TiO}_{2}$ deposition were cleaned stepwise by using detergent, distilled water, acetone, isopropanol and kept for UV-ozone treatment for 30 min. Deposition of $\mathrm{TiCl}_{4}$ was done by immersing electrodes into a $40 \mathrm{mM} \mathrm{TiCl}{ }_{4}$ aqueous solution at $70^{\circ} \mathrm{C}$ for $30 \mathrm{~min}$ and then washed with distilled water and ethanol. The photoanodes were then annealed at $500^{\circ} \mathrm{C}$ for $30 \mathrm{~min}$. After cooling, transparent $\mathrm{TiO}_{2}$ paste of particle size $20 \mathrm{~nm}$ was deposited followed by annealing at $125^{\circ} \mathrm{C}$ for $10 \mathrm{~min}$. Above this layer, $\mathrm{TiO}_{2}$ paste consisting of $\mathrm{TiO}_{2}$ particles of about $400 \mathrm{~nm}$ particle size was coated and annealed at $125^{\circ} \mathrm{C}$ for $10 \mathrm{~min}$. This was followed again by $\mathrm{TiCl}_{4}$ treatment and annealing. The electrodes were then put into programmed heating at $325^{\circ} \mathrm{C}$ for $15 \mathrm{~min}, 450^{\circ} \mathrm{C}$ for $15 \mathrm{~min}$, and $500^{\circ} \mathrm{C}$ for $30 \mathrm{~min}$ and slowly cooled down to room temperature. Electrodes were immersed into BT1 dye solution in THF $(0.3 \mathrm{mM})$ with or without co-adsorbents $(10 \mathrm{mM})$ and kept at room temperature for $15 \mathrm{~h}$. Counter electrodes were prepared by coating with a drop of $\mathrm{H}_{2} \mathrm{PtCl}_{6}$ solution ( $2 \mathrm{mg}$ of Pt in $1 \mathrm{~mL}$ ethanol) on FTO plates having pre-drilled holes, and cleaned using the same procedure as for photoanodes. The electrodes were assembled with hot press using $25 \mu \mathrm{m}$ surlyn spacer. The space in between both the electrodes were filled with liquid $\mathrm{I}^{-} / \mathrm{I}_{3}^{-}$electrolyte which was composed of various compositions of 1-butyl-3-methylimidazolium iodide (BMII), lithium iodide (LiI), iodine $\left(\mathrm{I}_{2}\right)$, guanidinium thiocyanate $(\mathrm{GuSCN})$ and 4-tert-butyl pyridine (tbp) in acetonitrile. The drilled holes were sealed with microscopic cover slide and surlyn to avoid electrolyte leakage. Three cells were fabricated for each condition and the cells were measured after keeping it for $12 \mathrm{~h}$ in dark.

The photovoltaic performance of the fabricated DSSC was measured using an AM $1.5 \mathrm{G}$ solar simulator (Newport Instruments, USA) equipped with a source meter (Keithley 2400) at $25^{\circ} \mathrm{C}$. The IPCE measurements of the devices were performed under DC mode using a $250 \mathrm{~W}$ xenon lamp coupled with Newport monochromator. A monochromatic beam was continuously irradiating on the sample and the current was measured using Keithley 6430 source meter. NISTcalibrated Si photodiode was used to find the incident power spectral response of the light. The $J-V$ properties of cells were measured using square shade mask with active area $0.25 \mathrm{~cm}^{2}$ (without mask active area is $0.36 \mathrm{~cm}^{2}$ ). The power of the simulated sunlight was calibrated by using a reference $S i$ photodiode supplied by Newport instruments. Open circuit voltage $\left(V_{\text {oc }}\right)$ decay measurements were done at open circuit. The cell was in the dark at the beginning of the measurement, and then the light was turned on until the voltage got stabilized, followed by switching the light off and recording the decay of photovoltage. Lifetime data was transformed from the voltage decay part of the measurement through previously reported methods. ${ }^{38}$ The EIS measurements of DSSC were carried out using a micro Autolab ( $\mu 3$ AUT70904) equipped with FRA mode under forward bias in the dark. The measurements were performed in a frequency range of 0.1 to $10^{5} \mathrm{~Hz}$ with ac amplitude of $10 \mathrm{mV}$.

\section{Results and Discussion}

\subsection{Absorption and emission properties of BT1 in solution and film state}

The normalized absorption spectra of BT1 in THF and spin coated film on a quartz plate are shown in figure $1 \mathrm{a}$. It exhibits an absorption band in the UV-visible region extending up to $500 \mathrm{~nm}$ with an absorption maximum at $388 \mathrm{~nm}$. The molar extinction coefficient was found to be $31,400 \mathrm{M}^{-1} \mathrm{~cm}^{-1}$, indicating reasonable light harvesting ability of the dye molecule. The absorption in the UV-visible region is mainly attributed to the 
(a)

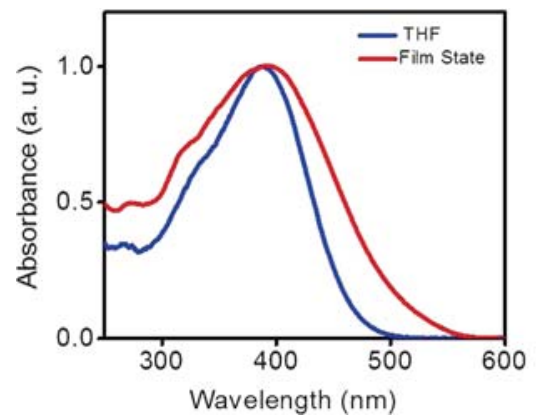

(b)

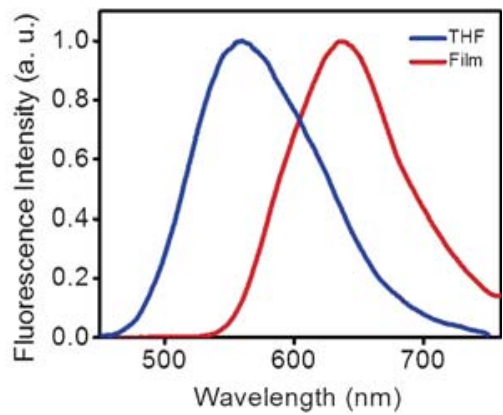

Figure 1. (a) Absorption and (b) emission spectra of BT1 in THF (Conc. = $10^{-5} \mathrm{M}, l=10 \mathrm{~mm}, \lambda_{\mathrm{ex}}=390 \mathrm{~nm}$ ) and film state (thickness, $102 \mathrm{~nm}$ ).

aromatic $\pi-\pi *$ transition with some contribution from the intramolecular charge transfer (ICT) between the donor and acceptor unit. Considerable broadening was observed in the film state on the quartz plate with the absorption extending upto $570 \mathrm{~nm}$, and the $\lambda_{\max }$ slightly red-shifted to $392 \mathrm{~nm}$. The absorption band-gap $E_{0,0}$ value was obtained from the intersection of absorption and emission spectra which was obtained as $2.5 \mathrm{eV} .{ }^{39}$ Absorption spectrum of BT1 on $\mathrm{TiO}_{2}$ is shown in Supplementary Information (SI) (figure S28) which is similar to the absorption spectrum on a quartz substrate. BT1 exhibited fluorescence emission maximum at 558 $\mathrm{nm}$ in solution and $636 \mathrm{~nm}$ in the film state (figure 1b). A red shift of about $78 \mathrm{~nm}$ was observed in the film compared to the solution state.

In order to study the role of aggregation in this system, absorption and emission experiments of BT1 with different ratio of THF:water mixtures were carried out. With 10\% THF-90\% water, the absorption maximum shifted to the red with a broadening as obtained in the film state which indicates that the BT1 undergoes aggregation (figure S29). In the case of emission spectra, BT1 exhibited a red shift of about $78 \mathrm{~nm}$ in the film state compared to the solution state. With increasing percentage of water (10\% THF- $90 \%$ water), fluorescence of BT1 was quenched and underwent a red shift of only about $30 \mathrm{~nm}$ (figure S30). Hence, the significant red-shift of the emission maximum in the film state could not be attributed to the aggregation of the molecules alone. In the solution state, there is a greater possibility for twisted conformation of the molecules to minimize the steric effects, whereas, in the film state more planarization of the chromophore backbone may happen. Such planarization results in increase in the effective conjugation length thereby shifting the emission maximum towards red. Hence, both aggregation and planarization of the backbone must be the reason for the significant red shift obtained in the film state of BT1.

\subsection{Electrochemical properties of $\boldsymbol{B T 1}$}

In order to examine the energy levels to ensure electron transfer at the $\mathrm{TiO}_{2} /$ dye/redox electrolyte interface, cyclic voltammetric studies were performed in DCM solution using $0.1 \mathrm{M}$ tetrabutylammonium hexafluorophosphate

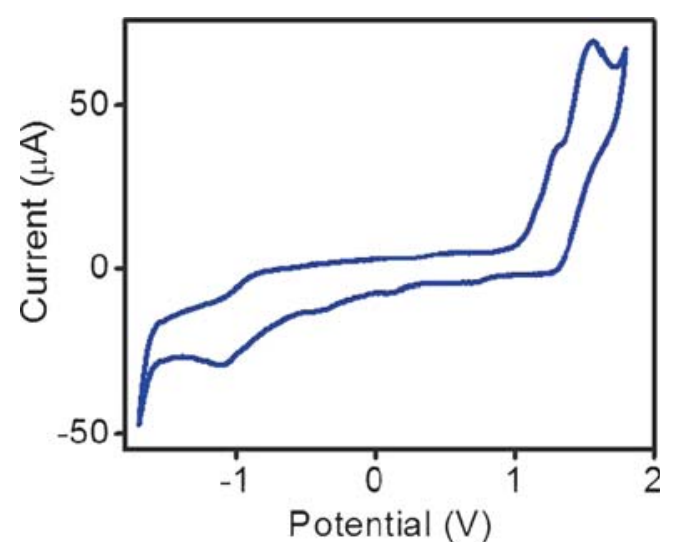

Figure 2. Cyclic Voltammogram of BT1 in DCM.

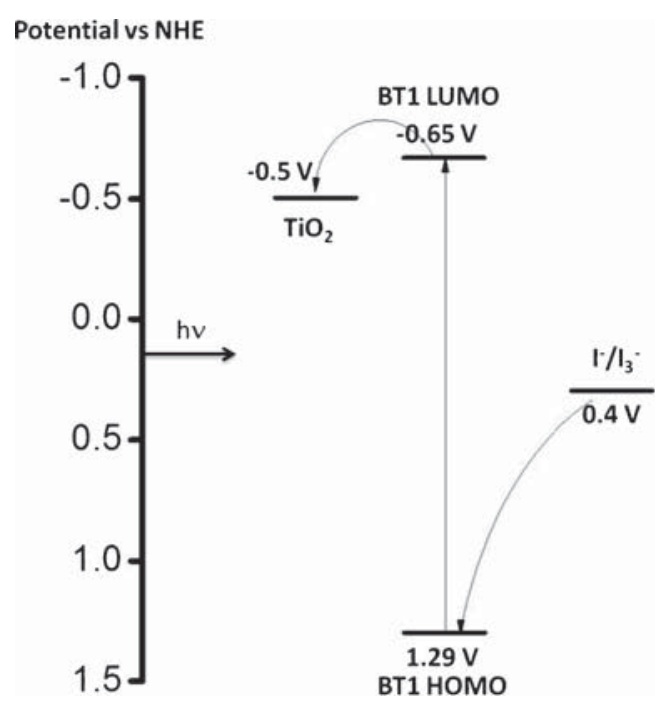

Scheme 2. Scheme showing the energetics of $\mathrm{TiO}_{2} /$ dye/ redox electrolyte interface. 
Table 1. Absorption, emission and electrochemical parameters of the dye, BT1.

\begin{tabular}{ccccccc}
\hline & $\lambda_{\text {abs }}(\mathrm{nm})$ & $\varepsilon\left(\mathrm{M}^{-1} \mathrm{~cm}^{-1)}\right.$ & $\lambda_{\mathrm{em}}(\mathrm{nm})$ & ${ }^{a} E_{0-0}(\mathrm{eV})$ & $E_{\text {HOMO }}(\mathrm{V}$ vs NHE $)$ & $E_{\text {LUMO }}(\mathrm{V}$ vs NHE $)$ \\
\hline BT1 & 388 & 31,400 & 558 & 1.98 & 1.29 & -0.65 \\
\hline
\end{tabular}

${ }^{a}$ band gap obtained from CV measurements

as the supporting electrolyte, $\mathrm{Pt}$ as the counter electrode, $\mathrm{Ag} / \mathrm{AgNO}_{3}$ as the reference electrode and glassy carbon as working electrode (figure 2). The reference electrode was calibrated using ferrocene/ferrocenium $\left(\mathrm{Fc} / \mathrm{Fc}^{+}\right)$redox couple as an external standard.

The oxidation potential of BT1 was calculated from the onset of the first oxidation peak, which was obtained as $1.07 \mathrm{~V}$ versus $\mathrm{Ag} / \mathrm{AgNO}_{3}$ and $0.53 \mathrm{~V}$ versus $\mathrm{Fc} / \mathrm{Fc}^{+}$. All the potentials measured were converted to NHE considering $\mathrm{Fc} / \mathrm{Fc}^{+}$as $+0.765 \mathrm{~V}$ vs NHE in DCM. ${ }^{40}$ Therefore, the ground state oxidation potential of BT1 was $1.29 \mathrm{~V}$ vs NHE, which corresponds to the ground state energy level. The excited state energy was calculated from the reduction potential and the value obtained was $-0.65 \mathrm{~V}$ vs NHE, which corresponds to the excited state energy level. This ground and excited energy levels were exactly placed within the energy requirements for electron transfer at electrolyte/TiO interfaces. As shown in scheme 2, the HOMO level of BT1 is more positive than the electrolyte, indicating that the oxidized dye can be efficiently regenerated by the redox species in the electrolyte. The excited state energy level is considerably more negative than the $\mathrm{TiO}_{2}$ implying electron injection from the excited dye into the conduction band of $\mathrm{TiO}_{2}$ is energetically favorable. All the absorption, emission and electrochemical parameters are shown in table 1 .

\subsection{Absorption, emission and energy levels of the co-adsorbents, $\mathbf{T P 1}$ and $\mathbf{T P 2}$}

Photophysical characterization of the newly prepared co-adsorbents, TP1 and TP2 were carried out. TP1 exhibits absorption in the range of $250-450 \mathrm{~nm}$ with $\lambda_{\max }$ at $374 \mathrm{~nm}$ and TP2 in the range of 250-500 nm with $\lambda_{\max }$ at $384 \mathrm{~nm}$. TP1 and TP2 exhibit emission maximum at 451 and $524 \mathrm{~nm}$, respectively. HOMO and LUMO values were obtained from the DFT calculations.
All the above parameters of the co-adsorbents, TP1 and TP2 are shown in table 2. Absorption spectra are given in the supporting information (figure S31).

\subsection{DFT calculations}

To further understand the electronic properties of BT1, DFT calculations were performed at the B3LYP/6-31G* level and the optimized HOMO and LUMO of the neutral state of BT1 in vacuum. The molecule is designed in such a way that it creates an energy level gradient from benzothiophene (donor) to bithiazole (weak acceptor) to cyano acrylic acid (strong acceptor). As a result, it was expected that the electron distribution of the HOMO should be mainly located on the benzothiophene unit, whereas that of LUMO mainly located along the acceptor cyanoacetic acid unit. The optimized HOMO and LUMO of BT1 obtained by DFT calculation proved this assumption (figure 3). The optimized structure of the molecule with dihedral angles of various bonds is shown in figure $3 \mathrm{~b}$. The dihedral angles between the bithiazole and two bridging thiophene units are $65.17^{\circ}$ and $88.22^{\circ}$.

\subsection{Photovoltaic properties}

Photovoltaic performances of BT1 as DSSC sensitizer were evaluated in the absence and presence of co-adsorbents. The BT1-coated $\mathrm{TiO}_{2}$ film was used as the working electrode, platinized fluorine-doped tin oxide (FTO) glass as the counter electrode. The electrolyte composition consists of mixed solution of $0.6 \mathrm{M}$ BMII, 0.1 M LiI, 0.05 $\mathrm{M} \mathrm{I}_{2}$, 0.5 M TBP. Photocurrentvoltage $(J-V)$ plots of the cells based on BT1 with different co-adsorbents are shown in figure $4 \mathrm{a}$ and electron lifetimes for the corresponding data are shown in figure $4 \mathrm{~b}$. The detailed parameters such as short circuit current density $\left(J_{\mathrm{SC}}\right)$, open-circuit voltage $\left(V_{\mathrm{OC}}\right)$, fill

Table 2. Absorption, emission and energy levels of the co-adsorbents.

\begin{tabular}{ccccccc}
\hline & $\lambda_{\text {abs }}(\mathrm{nm})$ & $\varepsilon\left(\mathrm{M}^{-1} \mathrm{~cm}^{-1)}\right.$ & $\lambda_{\text {em }}(\mathrm{nm})$ & $E_{0-0}{ }^{\mathrm{a}}(\mathrm{eV})$ & $E_{\text {HOMO }}(\mathrm{eV})$ & $E_{\mathrm{LUMO}}(\mathrm{eV})$ \\
\hline TP1 & 374 & 22,000 & 451 & 3.37 & -5.99 & -2.61 \\
TP2 & 384 & 9000 & 524 & 3.18 & -5.85 & -2.65 \\
\hline
\end{tabular}

${ }^{a}$ Band gap energy obtained from DFT calculations 


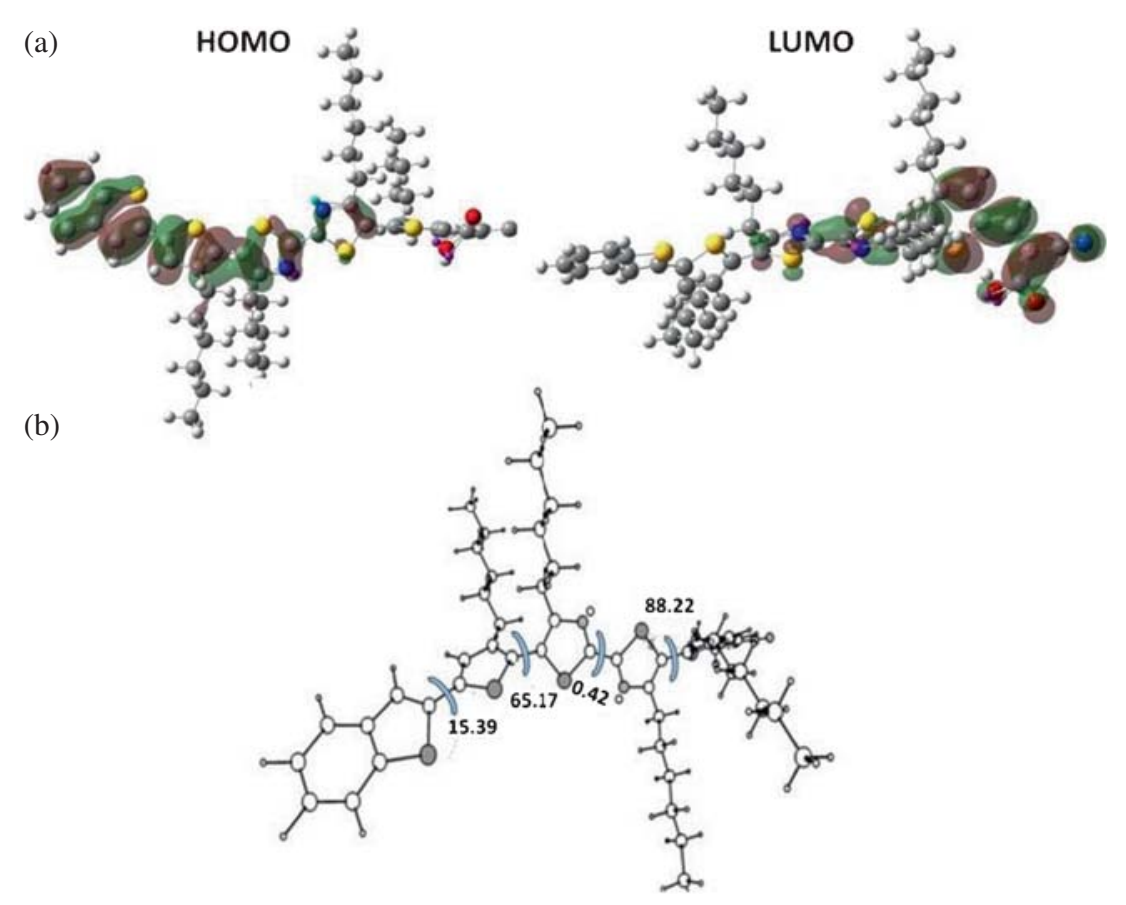

Figure 3. (a) HOMO and LUMO levels of the energy minimized structure of BT1 and (b) optimized structure obtained from DFT calculations.

factor $(F F)$ and photovoltaic conversion efficiency $(\eta)$ are summarized in table 3. The cell based on BT1 in the presence of CDCA as co-adsorbent exhibited the highest $\eta$ of $1.25 \%\left(J_{\mathrm{SC}}=2.56 \mathrm{~mA} \mathrm{~cm}^{-2}, V_{\mathrm{OC}}=0.64\right.$ $\mathrm{V}, F F=0.76)$. The efficiency was slightly higher compared to the cell based on BT1 alone which was about $1.13 \%$. The cell of BT1 with other co-adsorbents such as TP1 and TP2 exhibited lower efficiency compared to BT1 alone. The incident photon-to-current conversion efficiency (IPCE) spectra are shown in figure 5. The solar cells based on BT1 alone exhibited action spectra in the range of 380-500 nm with the highest IPCE value of $33 \%$ at $400 \mathrm{~nm}$. The IPCE value reduced significantly to $13 \%$ and $20 \%$, respectively, in the presence of co-adsorbents TP1 and TP2, whereas, it slightly improved (35\%) in the presence of CDCA. BT1 showed better performance with CDCA, whereas the performances were lowered in the presence of coadsorbents TP1 and TP2. The results of IPCE measurements were in accordance with the photovoltaic performances.

There are two plausible explanations for the drop in the photovoltaic performance in the presence of coadsorbents TP1 and TP2, which are as follows: a) the competition between the dye and co-adsorbents for the $\mathrm{TiO}_{2}$ surface with intake of less dye and more (a)

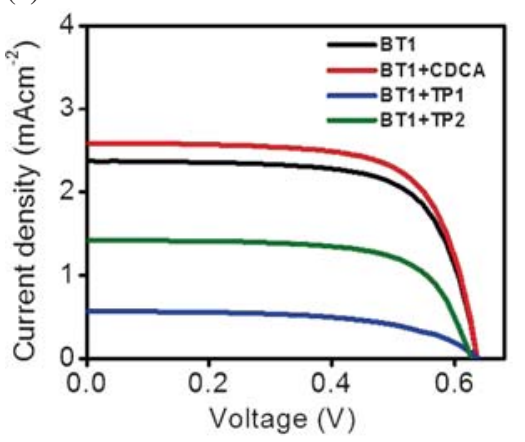

(b)

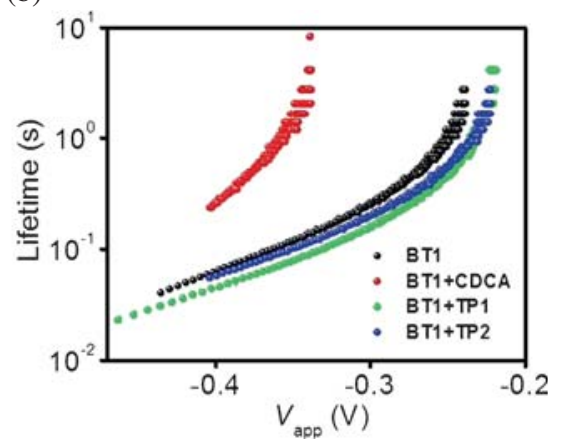

Figure 4. (a) Current-voltage characteristics. (b) Electron lifetimes of DSSCs sensitized by BT1 in the absence and presence of different coadsorbents, under irradiation of AM 1.5G simulated solar light. 
Table 3. Photovoltaic performance parameters of BT1 in the presence of different co-adsorbents.

\begin{tabular}{lcccc}
\hline & $J_{\mathrm{SC}}\left(\mathrm{mAcm}^{-2}\right)$ & $V_{\mathrm{OC}}(\mathrm{V})$ & $F F$ & $\eta$ \\
\hline BT1 Blone $^{[\mathrm{a}]}$ & 2.36 & 0.64 & 0.75 & 1.13 \\
BT1+TP1 $^{[\mathrm{a}]}$ & 0.53 & 0.64 & 0.56 & 0.20 \\
BT1+CD2 $^{[\mathrm{a}]}$ & 1.43 & 0.63 & 0.66 & 0.59 \\
BT1+CDCA $^{[\mathrm{a}]}$ & 2.56 & 0.64 & 0.76 & 1.25 \\
& 1.57 & 0.63 & 0.70 & 0.70 \\
\hline
\end{tabular}

Illumination: $100 \mathrm{mWcm}^{-2}$ simulated AM 1.5G solar light; composition of electrolyte: ${ }^{[a]}$ 0.6 M BMII, 0.1 M LiI, 0.05 $\mathrm{M} \mathrm{I}_{2}, 0.5 \mathrm{M}$ TBP. ${ }^{[\mathrm{b}]}$ Commercial electrolyte from dyesol.

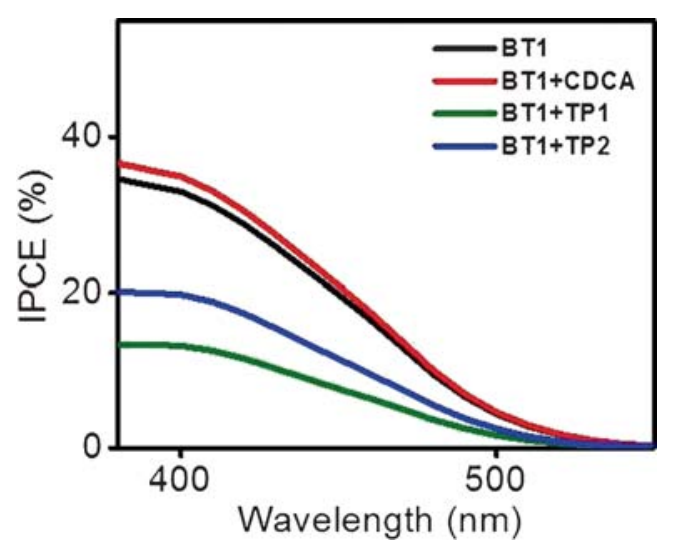

Figure 5. (a) IPCE plots of the DSSCs using BT1 in the absence and presence of different co-adsorbents.

co-adsorbents having lower absorption in the visible region, and b) less effective in preventing the aggregation of the dye particularly in the case of the short adsorbent, TP1. The electron lifetime plots in figure $4 \mathrm{~b}$ shows that BT1 in the presence of CDCA exhibited a higher lifetime than with other co-adsorbents since the former was expected to prevent recombination to a better extent than the latter. The enhancement in efficiency of BT1 co-adsorbed with CDCA could be attributed to the reduction in back electron transfer which is evident from the electron lifetime measurements as well as from the electrochemical impedance spectra.

Electrochemical impedance spectroscopy was employed to study the interfacial charge recombination in DSSC under dark condition. ${ }^{41-43}$ EIS Nyquist plots for DSSCs based on BT1 with different co-adsorbents are shown in figure 6. The first semi-circle indicates charge transfer resistance at the Pt/electrolyte interface. The major semi-circle shown in the Nyquist plot corresponds to the electron transport resistance at the $\mathrm{TiO}_{2}$ /dye/electrolyte interface which implies the resistance to recombination between electrons in $\mathrm{TiO}_{2}$ conduction band and oxidized $\mathrm{I}_{3}{ }^{-}$species in electrolyte. The

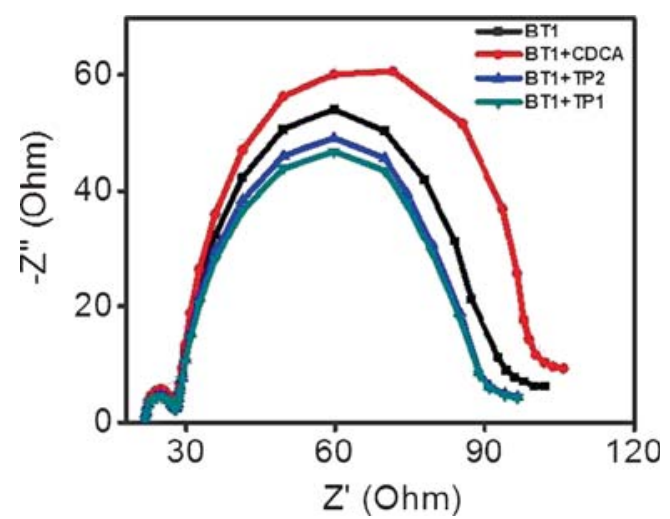

Figure 6. EIS Nyquist plots for DSSCs based on BT1 with various co-adsorbents measured at $-0.65 \mathrm{~V}$ forward bias in the dark.

larger the semi-circle, slower is the recombination kinetics. It is evident from figure 6 that BT1 co-adsorbed with CDCA exhibits higher recombination resistance which is consistent with the electron lifetime plots given in figure 4(b). Increase in charge recombination resistance resulted in increased electron lifetime by suppressing back electron transfer thereby enhancing photovoltaic performance for BT1 co-adsorbed with CDCA in comparison with other two co-adsorbents.

Literature reports suggest that metal-free, thiophene based systems exhibited enhancement in efficiency by incorporating co-adsorbents. ${ }^{20,25,44-48}$ A Triphenylamine based sensitizer containing thiophene as a $\pi$-bridge exhibited an increase in efficiency of $45 \%$ in the presence of CDCA. ${ }^{25}$ Multifunctional co-adsorbents with naphthalene and anthracene as $\pi$-conjugated aryl unit exhibited significant enhancement in photovoltaic parameters by suppressing charge recombination and increasing electron lifetime. ${ }^{47} 43-86 \%$ enhancement in efficiency was obtained with a bithiazole based DSSC in presence of CDCA. ${ }^{48}$ In the present work, the photoconversion efficiency of BT1 increased by $11 \%$ in the presence of CDCA. Nevertheless, the PCE of the BT1 dye is low when compared to several systems reported in the literature. This might be attributed to the low $J_{\mathrm{SC}}$ value which arises from the lower absorption efficiency of BT1 in the visible region. As evident from the energy minimized structure, the significant twist in the chromophore backbone which reduces the effective conjugation length, might be one contributing factor for this. Problem associated with low absorptivity could be partially solved by selecting a stronger donor instead of benzothiophene. Stronger donor units may improve the extinction coefficient and increase ICT character yielding a broad coverage in the visible spectrum. It is also anticipated that a change in the electrolyte system may enhance the photovoltaic efficiency. 


\section{Conclusions}

A new metal-free organic dye based on bithiazole and thiophene units containing cyanoacrylic acid as the anchoring group was synthesized. Detailed photophysical and DSSC device characterization has been carried out. The effect of different co-adsorbents on DSSC performance for BT1 was examined. The solar cell performance of BT1 was enhanced in the presence of CDCA, whereas it declined in the presence of other thiophene based co-adsorbents, TP1 and TP2.

\section{Supplementary Information}

Scheme showing the coadsorbents preventing recombination, synthesis of TP1 and TP2, spectral characterization data for all new compounds, absorption spectra of BT1 on $\mathrm{TiO}_{2}$, absorption and emission spectra of TP1 and TP2 and detailed photovoltaic parameters are available at www.ias.ac.in/chemsci.

\section{Acknowledgements}

B.B. thanks DST Fast Track Young Scientist Fellowship (SB/FT/CS-005/2013) for financial support. S.S. gratefully acknowledges financial support from DSTINSPIRE Faculty Award (IFA 13-CH-115). V.C.N. thanks DST for Ramanujan Fellowship (SR/S2/RJN133/2012). The authors acknowledge MNRE for financial support under CSIR-TAPSUN program. J.S.P. and T.G. are grateful to UGC for the junior research fellowships.

\section{References}

1. Gong J, Liang J and Sumathy K 2012 Renewable Sustainable Energy Rev. 165848

2. Hagfeldt A, Boschloo G, Sun L, Kloo L and Pettersson H 2010 Chem. Rev. 1106595

3. Hagfeldt A and Grätzel M 2000 Acc. Chem. Res. 33 269

4. Wang H, Liu Y, Li M, Huang H, Xu H M, Hong R J and Shen H 2010 Optoelectron. Adv. Mater. Rapid Commun. 41166

5. Ye M, Wen X, Wang M, Iocozzia J, Zhang N, Lin C and Lin Z 2015 Mater. Today 18155

6. Zhang L and Cole J M 2015 ACS Appl. Mater. Interfaces 73427

7. Jella T, Srikanth M, Bolligarla R, Soujanya Y, Singh S P and Giribabu L 2015 Dalton Trans. DOI: $10.1039 / \mathrm{c} 5 \mathrm{dt} 02074 \mathrm{c}$

8. Grätzel M 2009 Acc. Chem. Res. 421788
9. Chen C Y, Wang M, Li J Y, Pootrakulchote N, Alibabaei L, Ngoc-Le C H, Decoppet J D, Tsai J H, Grätzel C, Wu C G, Zakeeruddin S M and Grätzel M 2009 ACS Nano 3 3103

10. Wang S-W, Chou C-C, Hu F-C, Wu K-L, Chi Y, Clifford J N, Palomares E, Liu S-H, Chou P-T, Wei T-C and Hsiao T-Y 2014 J. Mater. Chem. A 217618

11. Mathew S, Yella A, Gao P, Humphry-Baker R, Curchod B F, Ashari-Astani N, Tavernelli I, Rothlisberger U, Nazeeruddin M K and Grätzel M 2014 Nature Chem. 6242

12. Yella A, Lee H W, Tsao H N, Yi C, Chandiran A K, Nazeeruddin M K, Diau E W, Yeh C Y, Zakeeruddin S M and Grätzel M 2011 Science 334629

13. Duvva N, Kanaparthi R K, Kandhadi J, Marotta G, Salvotri P, Angelis F D and Giribabu 2015 J. Chem. Sci. 127383

14. Zhu W, Wu Y, Wang S, Li W, Li X and Chen J 2011 Wang Z S and Tian H Adv. Funct. Mater. 21756

15. Qu S, Qin C, Islam A, Wu Y, Zhu W, Hua J, Tian H and Han L 2012 Chem. Commun. 486972

16. Hung W-I, Liao Y-Y, Lee T-H, Ting Y-C, Ni J-S, Kao W-S, Lin J T, Wei T-C and Yen Y-S 2015 Chem. Commun. 512152

17. Li S R, Lee C P, Kuo H T, Ho K C and Sun S S 2012 Chem. -A Eur. J. 1812085

18. Lai H, Hong J, Liu P, Yuan C, Li Y and Fang Q 2012 RSC Adv. 22427

19. Soman S, Rahim M A, Lingamoorthy S, Suresh C H and Das S 2015 Phys. Chem. Chem. Phys. DOI: $10.1039 / \mathrm{c} 5 \mathrm{cp} 03371 \mathrm{c}$

20. Tamilavan V, Kim A -Y, Kim H -B, Kang M and Hyun M H 2014 Tetrahedron 70371

21. He J, Hua J, Hu G, Jiang X, Gong H and Li C 2014 Dyes Pigm. 10475

22. Liu X, Cao Z, Huang H, Liu X, Tan Y, Chen H, Pei Y and Tan S 2014 J. Power Sources 248400

23. Haid S, Marszalek M, Mishra A, Wielopolski M, Teuscher J, Moser J -E, Humphry-Baker R, Zakeeruddin S M, Grätzel M and Bäuerle P 2012 Adv. Funct. Mater. 221291

24. Zhang W, Feng Q, Wang Z -S and Zhou G 2013 Chem. Asian J. 8939

25. Shi J, Chai Z, Tang R, Hua J, Li Q and Li Z 2015 Sci. China Chem. 581144

26. Zhou P, Dang D, Wang Q, Duan X, Xiao M, Tao Q, Tan H, Yang R and Zhu W 2015 J. Mater. Chem. A 3 13568

27. Narayanaswamy K, Swetha T, Kapil G, Pandey S. S, Hayase S and Singh S P 2015 Electrochim. Acta 169256

28. Zhu L, Yang H B, Zhong C and Li C 2014 Dyes Pigm. 10597

29. Jeona B C, Kima M S, Chob M J, Choib D H, Ahna K -S and Kima J H 2014 Synthetic Met. 188130

30. Lin Y, Fan H, Li Y and Zhan X 2012 Adv. Mater. 24 3087

31. Lin Y, Cheng P, Liu Y, Shi Q, Hu W, Li Y and Zhan X 2012 Org. Electron. 13673

32. He J, Guo F, Li X, Wu W, Yang J and Hua J 2012 Chem. Eur. J. 187903

33. He J, Wu W, Hua J, Jiang Y, Qu S, Li J, Long Y and Tian H 2011 J. Mater. Chem. 216054 
34. Chen B S, Chen Y J and Chou P T 2011 J. Mater. Chem. 24090

35. Lai L-F, Ho C-L, Chen Y-C, Wu W-J, Dai F-R, Chui CH, Huang S-P, Guo K-P, Lin J T, Tian H, Yang S-H and Wong W-Y 2013 Dyes Pigm. 96516

36. Yen Y -S, Lin T -Y, Hsu C - Y, Chen Y -C, Chou H -H, Tsai C and Lin J T 2013 Org. Electron. 142546

37. Balan B, Vijayakumar C, Saeki A, Koizumi Y and Seki S 2012 Macromolecules 452709

38. Soman S, Xie Y and Hamann T W 2014 Polyhedron 82 139

39. Lakowicz J R 1999 In Principles of Fluorescence Spectroscopy (Dordrecht: Kluwer Academic)

40. Robson K C D, Sporinova B, Koivisto B D, Schott E, Brown D G and Berlinguette C P 2011 Inorg. Chem. 50 6019

41. Wang Q, Moser J -E and Gratzel M 2005 J. Phys. Chem. B 10914945
42. Wu G, Kong F, Zhang Y, Zhang X, Li J, Chen W, Liu W, Ding Y, Zhang C, Zhang B, Yao J and Dai S $2014 \mathrm{~J}$. Phys. Chem. C 1188756

43. Cisneros R, Beley M, Fauvarque J-F and Lapicque F 2015 Electrochim. Acta $\mathbf{1 7 1} 49$

44. Tamilavan V, Chob N, Kimb C, Kob J and Hyuna M H 2012 Synthetic Met. 1622155

45. Tamilavan V, Kimb A-Y, Leeb H, Kima H -B, Kima S, Kang M and Hyuna M H 2014 Synthetic Met. 191 141

46. Guo F, He J, Qu S, Li J, Zhang Q, Wu W and Hua J 2013 RSC Adv. 315900

47. Choi I T, You B S, Eom Y K, Ju M J, Choi W S, Kang S H, Kang M S, Seo K D, Hong J Y, Song S H, Yang J -W and Kim H K 2014 Org. Electron. 15 3316

48. Yen Y-S, Lin T-Y, Hsu C-Y, Chen Y-C, Chou H-H, Tsai C and Lin J T 2013 Org. Electron. 142546 